\title{
LETTERS
}

\section{The authors respond to "Routine use of episiotomy with forceps should not be encouraged"}

We thank Drs. Klein and Kaczorowski for their interest in our article..$^{1,2}$ Although we found some of their arguments distracting and dated, we welcome this opportunity to clarify our position.

Klein and Kaczorowski are correct in pointing out that our analysis focused on hospital deliveries, which included about 98\% of all deliveries in Canada (excluding Quebec). ${ }^{3}$ We characterized trends in episiotomy use in Canada and are unaware of data sources that contain such information for home births. Comparing differences in rates of episiotomy, operative vaginal delivery and obstetric anal sphincter injury in our study with those in the study by Janssen and colleagues ${ }^{4}$ is not particularly meaningful, as the latter was restricted to women with low obstetric risk. Additionally, the study by Janssen and colleagues included deliveries from 15 to 20 years ago, when rates of obstetric anal sphincter injury were significantly lower. ${ }^{5}$

Klein and Kaczorowski appear to have missed the main conclusion of our study, which showed a) that episiotomy use in Canada has declined among both spontaneous and operative vaginal deliveries and b) that episiotomy use in spontaneous vaginal deliveries increases the risk of obstetric anal sphincter injury, while episiotomy use in operative vaginal deliveries protects against obstetric anal sphincter injury. The finding that episiotomy use increases risk of obstetric anal sphincter injury in spontaneous vaginal deliveries has been documented in several randomized trials ${ }^{6}$ and is not under debate: the guideline from The Society of Obstetricians and Gynaecologists of $\mathrm{Canada}^{7}$ on the use of episiotomy in spontaneous vaginal delivery already reflects the evidence. However, both the 2017 Cochrane review 6 on routine versus selective episiotomy use and the World Health Organization's 2018 guideline ${ }^{8}$ on intrapartum care emphasize that the role of episiotomy in operative vaginal delivery remains to be established. It is on this lat- ter issue that our study provides important evidence. The fact that forceps deliveries accounted for $2.9 \%$ of deliveries among nulliparous women and women with a vaginal birth after cesarean delivery is irrelevant, as the above-mentioned associations were evaluated among 66503 forceps deliveries.

The randomized trial of episiotomy use in North America by Klein and colleagues contributed to reducing unnecessary pain and rates of obstetric anal sphincter injury among women with spontaneous vaginal deliveries. ${ }^{9}$ However, this trial did not provide insight into the relation between episiotomy use and obstetric anal sphincter injury among operative vaginal deliveries, as it included a total of 20 forceps deliveries and was carried out 30 years ago, when median episiotomy was common practice. Similarly, reference to the study by Ecker and colleagues $^{10}$ is not helpful, partly because it was based on a crude analysis of 2041 deliveries occurring at a single institution between 1984 and 1994. Further, the study documented a sharp reduction in episiotomy rates among operative vaginal deliveries in nulliparous women from $96.5 \%$ in 1984 to $38.7 \%$ in 1994 , and a concurrent striking reduction in rates of fourth-degree perineal laceration from $14.8 \%$ in 1984 to $5.8 \%$ in 1994 (rates of third-degree tears were $28.3 \%$ in 1984 and $29.7 \%$ in 1994)..$^{10}$ The temporal reduction in fourth-degree perineal tears notwithstanding, these stratospheric rates of third- and fourth-degree perineal laceration have little bearing on present-day discourse in Canada, where the same rates in 2004-2017 were substantially lower (rate of third-degree tears $13.3 \%$ to $14.6 \%$ and rate of fourth-degree tears $2.1 \%$ to $2.2 \%$ after operative vaginal delivery among nulliparous women ${ }^{2}$ ).

We carried out additional analyses by the main maternity care provider responsible for the care during the delivery hospital admission (irrespective of who conducted the delivery), but the results did not alter the interpretation of our study results. Multivariable regression analyses among nulliparous women showed no significant differences in the association between episiotomy use and obstetric anal sphincter injury by provider type except among women delivering by vacuum (rate ratio 1.22, 95\% confidence interval $[\mathrm{Cl}] 1.02-1.48$ for midwives; rate ratio $0.88,95 \% \mathrm{Cl} 0.84-0.92$ for obstetricians; and rate ratio $0.89,95 \% \mathrm{Cl} 0.83-$ 0.96 for general practitioners). In the group of parous women without a previous cesarean delivery, the association between episiotomy and obstetric anal sphincter injury among spontaneous vaginal deliveries was significantly stronger among women with midwives as the main service provider (deliveries with midwives: rate ratio $4.42,95 \% \mathrm{Cl} 3.28-$ 5.95; obstetricians: rate ratio $2.58,95 \% \mathrm{Cl}$ 2.40-2.77; general practitioners: rate ratio $2.66,95 \% \mathrm{Cl} 2.33-3.03)$. Among women with a vaginal birth after cesarean delivery, the protective association between episiotomy use and obstetric anal sphincter injury among forceps deliveries was significantly different by provider type (deliveries with midwives as the main service provider: rate ratio $0.22,95 \% \mathrm{Cl} 0.08-0.59$; obstetricians: rate ratio $0.88,95 \% \mathrm{Cl} 0.69-1.12$; general practitioners: rate ratio $1.17,95 \% \mathrm{Cl}$ $0.76-1.81)$. This was also true among vaginally nulliparous women who had a vaginal birth after a cesarean delivery.

\section{Giulia M. Muraca PhD MPH}

Postdoctoral fellow, Clinical

Epidemiology Unit, Department of Medicine, Solna Karolinska Institutet, Stockholm, Sweden, and Department of Obstetrics and Gynaecology, University of British Columbia, Vancouver, BC

\section{K.S. Joseph MD PhD}

Professor, Department of Obstetrics and Gynaecology, University of British

Columbia, Vancouver, BC

- Cite as: CMAJ 2020 February 24; 192:E191-2. doi: 10.1503/cmaj.74565

\section{References}

1. Klein MC, Kaczorowski J. Routine use of episiotomy with forceps should not be encouraged [letter]. CMAJ 2020;192:E190. 
2. Muraca GM, Liu S, Sabr Y, et al. Episiotomy use among vaginal deliveries and the association with anal sphincter injury: a population-based retrospective cohort study. CMAJ 2019;191: E1149-58.

3. Live births and fetal deaths (stillbirths), by place of birth (hospital or non-hospital). Ottawa: Statistics Canada; 2019. Available: www150.statcan.gc.ca/ t1/tbl1/en/tv.action?pid=1310042901 (accessed 2019 Dec. 5).

4. Janssen PA, Saxell L, Page LA, et al. Outcomes of planned home birth with registered midwife versus planned hospital birth with midwife or physician. CMAJ 2009;181:377-83.

5. Muraca GM, Lisonkova S, Skoll A, et al. Ecological associations between operative vaginal delivery and obstetric and birth trauma. CMAJ 2018;190: E734-41.

6. Jiang H, Qian X, Carroli G, et al. Selective versus routine use of episiotomy for vaginal birth. Cochrane Database Syst Rev 2017;(2):CD000081.

7. Lee L, Dy J, Azzam H. Management of spontaneous labour at term in healthy women. J Obstet Gynaecol Can 2016;38:843-65.

8. WHO recommendations: intrapartum care for a positive childbirth experience. Geneva: World Health Organization; 2018.

9. Klein MC, Gauthier RJ, Jorgensen SH, et al. Does episiotomy prevent perineal trauma and pelvic floor relaxation? [published erratum Online J Curr Clin Trials 1992 Sep 12;Doc No 20] Online J Curr Clin Trials 1992; July 1;Doc No 10.

10. Ecker JL, Tan WM, Bansal RJ, et al. Is there a benefit to episiotomy at operative vaginal delivery? Observations over ten years in a stable population. Am J Obstet Gynecol 1997;176:411-4.

Competing interests: None declared. 